\title{
Agriculture and Health Sectors Collaborate in Addressing Population Health
}

\author{
Arthur Kaufman, $M D^{1}$ \\ Jon Boren, $\mathrm{PhD}^{2}$ \\ Sonja Koukel, $\mathrm{PbD}^{3}$ \\ Francisco Ronquillo, MA, $P A^{1}$ \\ Cindy Davies, $M A^{4}$ \\ Carolina Nkouaga, $M P H^{1}$ \\ 'University of New Mexico Health \\ Sciences Center, University of New \\ Mexico, Albuquerque, New Mexico \\ ${ }^{2}$ College of Agricultural, Consumer and \\ Environmental Sciences, New Mexico State \\ University, Las Cruces, New Mexico \\ ${ }^{3}$ Extension Family and Consumer Sciences \\ Department, New Mexico State University, \\ Las Cruces, New Mexico \\ ${ }^{4}$ Bernalillo County Cooperative Extension \\ Service, New Mexico State University, Las \\ Cruces, New Mexico
}

\begin{abstract}
PURPOSE Population health is of growing importance in the changing health care environment. The Cooperative Extension Service, housed in each state's land grant university, has a major impact on population health through its many communitybased efforts, including the Supplemental Nutrition Assistance Program - Education (SNAP-Ed) nutrition programs, 4-H youth engagement, health and wellness education, and community development. Can the agricultural and health sectors, which usually operate in parallel, mostly unknown to each other, collaborate to address population health? We set out to provide an overview of the collaboration between the Cooperative Extension Service and the health sector in various states and describe a case study of 1 model as it developed in New Mexico.
\end{abstract}

METHODS We conducted a literature review and personally contacted states in which the Cooperative Extension Service is collaborating on a "Health Extension" model with academic health centers or their health systems. We surveyed 6 states in which Health Extension models are being piloted as to their different approaches. For a case study of collaboration in New Mexico, we drew on interviews with the leadership of New Mexico State University's Cooperative Extension Service in the College of Agricultural, Consumer and Environmental Sciences; the University of New Mexico (UNM) Health Science Center's Office for Community Health; and the personal experiences of frontline Cooperative Extension agents and UNM Health Extension officers who collaborated on community projects.

RESULTS A growing number of states are linking the agricultural Cooperative Extension Service with academic health centers and with the health care system. In New Mexico, the UNM academic health center has created "Health Extension Rural Offices" based on principles of the Cooperative Extension model. Today, these 2 systems are working collaboratively to address unmet population health needs in their communities. Nationally, the Cooperative Extension Service has formed a steering committee to guide its movement into the health arena.

CONCLUSION Resources of the agricultural and health sectors offer communities complementary expertise and resources to address adverse population health outcomes. The collaboration between Cooperative Extension and the health sector is 1 manifestation of this emerging collaboration model termed Health Extension. Initial skepticism and protection of funding sources and leadership roles can be overcome with shared funding from new sources, shared priority setting and decision making, and the initiation of practical, collaborative projects that build personal relationships and trust.

Ann Fam Med 2017;15:475-480. https://doi.org/10.1370/afm.2087.

\section{BACKGROUND}

$\mathrm{T}$ he Cooperative Extension Service, administered by the land-grant university in each state, contributes to the health and social welfare of our nation. The service functions in every county in the United States alongside the health sector, yet the 2 systems usually work in parallel, unknown to each other. This disconnect between 2 major sectors of our society should be redressed by creating a partnership that brings together their complementary strengths to address critical health and social needs in our communities. 
There is a growing national call for an allocation of health system resources to address population health needs. ${ }^{1-4}$ Some approaches to addressing this need include broadening the training and scope of work of health professionals, ${ }^{5,6}$ and expanding the health care team to include community health workers who offer skills in working with the cultural, ethnic, or geographic populations from which they come. ${ }^{7,8}$ Most who work in the health sector, however, are unaware of the benefit to population health represented by each state's Cooperative Extension Service, a resource with a lengthy history of addressing communities' health, social, and economic needs. For example, the Cooperative Extension Service advances rural development by helping growers increase crop yields; improves quality of life for individuals, families, and communities through its Family and Consumer Sciences programs (formerly "home economics"); and fosters youth development and educational success through its $4-\mathrm{H}$ youth programs.

Can the health system improve how it addresses population health by collaborating with the Cooperative Extension Service? Such a collaboration could be of particular interest and value to family physicians and to academic family medicine departments, which already promote partnerships with other sectors, such as the public school systems, social service agencies, and legislative bodies. The authors will provide an overview of the collaboration between the Cooperative Extension Service and Health Extension services in several states and describe 1 model as it developed in New Mexico.

\section{Parallel Movements to Address Population Health}

Two parallel movements have led to the collaboration between the agricultural and health sectors to address the social determinants of health and improve population health: the expansion of the Cooperative Extension Service's focus on health, and the emergence of extension-style models within the health sector.

\section{Cooperative Extension Expanding its Health Focus} In a national report, Cooperative Extension leadership noted that county-based Extension offices "have the community presence and local credibility needed to influence the social, economic, and environmental determinants of health." Further, the report said that "given the national trends in health, and the current assets of Extension, including the ability to be responsive to emerging needs, it is a critical time to create a new programmatic focus." ${ }^{\prime \prime}$

Cooperative Extension is thus providing programs that respond to the emerging health needs of individuals, families, and the public at large. ${ }^{10}$ To this end, the Extension Committee on Organization \& Policy
(ECOP), an elected committee that represents the 57 state and territorial Cooperative Extension systems in policy decisions and provides a nationwide program on organizational leadership, established a Health Task Force in 2012. The coalition formed action teams that are focusing on health programming areas identified in the National Framework for Health and Wellness (adopted in 2014), areas that improve population health by addressing social determinants of health, including health literacy, health insurance literacy, and chronic disease prevention and management among others. ${ }^{9}$

\section{Extension Models Emerging in Health Sector}

A parallel movement within the health sector and academic health centers is working to adapt the Cooperative Extension Service model to health care delivery. This approach places health officers across the participating states to work with local communities to identify priority health problems and to mobilize resources to address those priorities. ${ }^{11,12}$ This Health Extension model was incorporated into the Affordable Care Act as Section 5405-the "Primary Care Extension Program"- based on innovations in New Mexico and Oklahoma. ${ }^{13}$ Two federal grants emerged from this section, both funded by the Agency for Healthcare Research and Quality. The IMPaCT grant was issued to 4 states (award \#R018HS020890) and the EvidenceNOW grant issued to 7 multi-state cooperatives. (\#R018HS023904-01).

After a decade during which the Health Extension model developed in parallel with but apart from the traditional Cooperative Extension Service, a more formal collaboration between health science centers and the Cooperative Extension Service is emerging. This is timely, since both are changing in important ways to become more efficient and improve population health outcomes. Cooperative Extension is no longer concerned only with agriculture, and the health system is moving beyond a medical model. The 2 sectors are sharing a common path to improve community health by addressing social determinants of health.

\section{Overview of Evaluation Process}

In order to understand the nature of the collaboration taking place between Cooperative Extension and Health Extension efforts around the country, we conducted a literature review and personally contacted states in which the Cooperative Extension Service is collaborating with the state academic health centers or health systems. We surveyed 6 states in which the Health Extension model is being piloted to identify their different approaches. To develop a case study of New Mexico's collaboration, we interviewed the leadership of the New Mexico State University (NMSU) 
Cooperative Extension Service in the College of Agricultural, Consumer and Environmental Sciences; the leadership of the University of New Mexico (UNM) Health Sciences Center Office for Community Health; and county Cooperative Extension agents and UNM Health Extension Regional Officers (HEROs) who collaborate on community projects.

\section{The National Scene}

Today, at least 18 states are implementing Health Extension models. A number of other states are exploring various models and partnerships to expand the ability of the Cooperative Extension Service and academic health science centers to better address population health.

As this partnership between Cooperative Extension and health science centers has grown, the emerging Health Extension model has been presented nationally at conferences in both professional fields. Collaboratively, leaders from both Cooperative Extension and academic health centers from various states have presented at 2 consecutive Cooperative Extension National Health Outreach conferences (formerly known as Priester conferences), as well as 2 national medical meetings - the National Primary Care Extension Program Meeting ${ }^{13}$ and the national Beyond Flexner Alliance Conference. ${ }^{4}$

Academic health centers in Oregon, Washington, Oklahoma, Colorado, and New Mexico are some of those implementing aspects of Health Extension. Learning from each other's experiences, they have shared variations in approaches taken-from the creation of non-profit county improvement organizations to the employment of health extension coordinators as "practice enhancement research coordinators," the creation of "regional health connectors" in a state's State Innovation Model Grant, and the deployment of health extenders to address social determinants of health in the state's Accountable Communities of Health. The collaboration between various forms of Health Extension with Cooperative Extension is quite new.

The Kentucky Cooperative Extension Service, based at the University of Kentucky, has created a transformative partnership with the university's school of public health and colleges of social work, pharmacy, dentistry, nursing, and medicine along with community partners. The resulting Health Education through Extension Leadership program has 3 objectives: educate and empower individuals and families to adopt healthy behaviors and lifestyles, build community capacity to improve health, and educate consumers to make informed health choices. The wide range of community interventions resulting from the program include Get Moving Kentucky (addressing physical inactivity), Calming the Storm (addressing social and emotional well-being), and Walk Your Land (encouraging farmers and other landowners to make sure their property is not housing methamphetamine labs).

With $\$ 10$ million of state funding, Healthy South Texas was formed, which combines the expertise of the Texas A\&M Health Science Center and local hospitals and clinics. The initiative capitalizes on the statewide reach of the Texas A\&M AgriLife Extension Service to promote preventive health at the community level. From a broad coalition of stakeholders, it builds comprehensive, multi-professional teams including expertise in medicine, nursing, public health, architecture, bioscience, and technology. Aligning their objectives with the national ECOP goal, they intend to do for health what Cooperative Extension has done for agriculture for the past century. They focus on educating individuals and their families on evidence-based ways of taking personal responsibility for preventing illness. They will be tracking health care costs and the status of preventable conditions.

The Michigan State University Extension and College of Human Medicine have partnered to improve health outcomes for Michigan residents. The partnership has fostered interdisciplinary and collaborative outreach programs intended to influence the social, economic, and environmental determinants of health. The 2 share a research agenda geared toward measurable improvement in health. Extension brings the community presence and credibility needed to influence population health. The College of Human Medicine's expertise in research will be bolstered by the subject recruiting capabilities of Cooperative Extension.

\section{Case Study in New Mexico}

A collaboration between the UNM Health Sciences Center and the NMSU Cooperative Extension Service network exemplifies the developing partnership between Extension Services and Health Centers. Although developing joint programs across different university systems has its challenges, the coupling of these institutions has led to substantial improvement in New Mexico health programs. A memorandum of understanding was signed in 2013 between NMSU and UNM. The memorandum built on the missions of the 2 organizations to articulate goals and objectives, and agreed-upon deliverables for future collaborations, initiatives, and programs. The number of successful initiatives developed through this formal partnership demonstrates the potential of this relatively new model of "Health Extension."

\section{Community Education Concerning}

Medicaid Expansion

In March 2014, UNM received a contract from the New Mexico Health Insurance Exchange to work 
through the higher education system to maximize enrollment and provide health insurance coverage information. While UNM had strong links in various parts of the state, it did not have the extent and depth of ties to many rural communities enjoyed by the NMSU Cooperative Extension. So the latter received a subcontract from UNM to disseminate Health Insurance Exchange educational and marketing materials to 5 rural counties. County Family \& Consumer Sciences agents provided information on where and how individuals and small businesses could enroll in health insurance coverage. The Cooperative Extension agents held nearly 50 events disseminating health insurance marketplace information to more than 6,000 New Mexicans. Anecdotally, insurance enrollment, especially Medicaid enrollment, increased in rural communities as a result of this intense rural outreach education effort.

\section{Nutrition Education for Patients of Community Health Centers}

Most small community clinics or federally qualified health centers have a disproportionate percentage of patients who are indigent and who have high rates of obesity, diabetes, and hypertension. But these clinics can't afford to hire a nutritionist or health educator. In Albuquerque, the UNM HERO worked closely with neighborhood primary care clinics, and when the need for a nutritionist was identified, the HERO brokered a relationship between the largest clinic, which serves a largely immigrant, Hispanic population, and the local Cooperative Extension office. The clinic offered a clinic meeting space for health education programs. County Extension provided the dietician, nutrition educator, food supplies, and curriculum. This success of this mutually beneficial collaboration led to other clinics seeking to emulate this model.

\section{Support for Seniors}

The senior population is growing in New Mexico, and many of the seniors live on very limited budgets. Food insecurity and obesity are prevalent, so they need nutrition education. The concerned manager of a senior citizens center contacted the local HERO requesting a session for his center members on "Sugar and Its Harmful Effects on the Body." The seniors, accustomed to playing games like Bingo, working on crafts, and attending social events, were skeptical about having to sit through dry health talks. The HERO invited a Cooperative Extension dietetic intern to co-teach on health topics in a highly interactive and entertaining manner. The seniors' positive response led to a monthly health talk series based on topics picked by the seniors including "why do we need flu and shingles shots?," "what is a stroke?," and "what are healthy snacks for seniors with diabetes?" On the basis of this experience, 2 dieticians from the UNM program asked the local Extension Family \& Consumer Sciences agent for help offering educational programs for patients in other settings.

\section{Working With the Immigrant Community}

Health literacy, a particular challenge for the immigrant community, is believed to be a significant indicator of health. According to the National Academy on an Aging Society, only 12 percent of Americans are health literate. ${ }^{14}$ In an effort to address the correlation between low health literacy and poor health, HEROs and the Cooperative Extension Service are partnering with the Ventanilla de Salud program at the Mexican Consulate to offer healthy cooking demonstrations at the Consulate once a month. The intervention brings health information and cooking skills to participants via an interactive and dynamic approach in a culturally and linguistically appropriate manner. This replaces static handouts or information presented on a plasma screen. This is also a vehicle for introducing affordable, nutritious foods, mostly locally grown, into the diet of immigrants from Mexico. The sessions are held in the lobby while clients wait for their turn to process their transactions.

\section{Working With the Public Health and Hospitals} In 2015, the New Mexico Department of Health received a $\$ 2$ million planning grant during the third round of Centers for Medicare and Medicaid funding for its State Innovations Model grant. A key component of the plan was the creation of regional health "hubs" across the state anchored by the HERO program, the Cooperative Extension Service, the Comprehensive County Health Planning Councils, community health worker representatives, community hospitals and health systems. While the third-round grants were never funded, the backbone model, built on the HERO-Cooperative Extension collaboration, triggered local expressions of the planned regional collaboration. For example, some non-profit hospitals demonstrated a public benefit by subsidizing community health studies and action plans which included input from UNM HEROs and Cooperative Extension.

\section{Challenges}

The term Health Extension faced opposition from Cooperative Extension services at first. In some cases, Cooperative Extension leaders thought their successful organizations were being threatened-not only in that their name was being hijacked by those in the academic health system but also in that the new type of initiative would siphon off scarce federal and state funds. The similarity of the names also created confusion in communities about whether the 2 programs were connected 
or redundant. It was suggested that Health Extension be renamed Health Outreach or another less competitive and confusing term. But the term Health Extension had become quickly acknowledged within the academic health center community nationally, so it remained, while proponents tried to help stakeholders understand that Health Extension was complementary to and an outgrowth of Cooperative Extension. Invitations to each other's national meetings and shared grant funding have also helped alleviate the initial concern.

Area Health Education Centers (AHECs) mounted a more public opposition. When the first AHRQ $\mathrm{IMPaCT}$ grant announcement was released, many in AHEC's national leadership declared AHEC as the rightful recipient of these funds, with the new Health Extension collaborative viewed as doing little more than what AHEC already does. This challenge was somewhat softened in New Mexico by the fact that the UNM HEROs and AHEC programs are administered by the same Office for Community Health. Many HEROs and AHEC field representatives were assigned both functions, and the Office for Community Health shared extramural grant resources with both programs

A collaboration between a land-grant and a flagship university in a single state presents its own unique challenges. They vie for the same state higher education budgets, they compete for bragging rights in sporting events, and they are both research universities recruiting from the same pool of student applicants. The culture of a highly decentralized, educationally-oriented Cooperative Extension Service was not an easy fit with a very centralized, service-oriented health system with its base in an academic health science center. It required leaders able to see that collaboration would be more beneficial than competition - that their collaboration would help the state's grossly under-resourced, under-performing health system, the faults of which were made more glaring after passage of the Affordable Care Act.

\section{Lessons Learned}

Collaboration between the Cooperative Extension Service and Health Extension services throughout the country offers several important lessons. First, the agricultural and health sectors offer communities complementary strengths to address unmet health and development needs. Initial skepticism regarding the value of partnering is overcome by small, frontline collaborative projects that build trust and jointly create solutions to local needs which would not have emerged if either party had been working alone. Second, threats to funding sources can be overcome by efforts at joint application for funding from new sources. Third, while initial successes occurred in rural areas where layers of bureaucracy are fewer and interdependence of com- munity members is more prevalent, urban partnerships have been found just as effective in identifying and creating jointly run programs. Fourth, as Cooperative Extension moves increasingly into the health field, a spotlight can be put on its previously unrecognized value to the health system by inviting innovators to national conferences and arranging for joint presentations and publications.

Collaboration between Cooperative Extension and Health Extension Rural Officers in New Mexico has grown in part because of their unique approach to creating a "community health partnership."15 The threat to large institutions of sharing resources, competing for funding, or jockeying for leadership roles was obviated by maintaining separate authorities and by aligning existing resources for greater benefit to both institutions as well as to communities. This threat is also mitigated by the way Cooperative Extension agents and HERO officers live and work in the communities served and the way the communities themselves dictate the knowledge and resources needed from the 2 systems. Sustainability of this partnership is enhanced by the shared value of outcomes-based advocacy, visionfocus balance, and community linkages- 3 of the 5 primary attributes/activities of sustained partnerships. ${ }^{16}$

\section{CONCLUSION}

To our knowledge, this is the first manuscript describing the collaboration between the relatively new Health Extension model and the agricultural model on which it was based, the Cooperative Extension Service, at the national level and in a sample state. A rich and growing body of experiences is emerging as more states' landgrant and flagship universities share their complementary resources in the service of population health.

Nationally, Cooperative Extension is assuming leadership in providing programs that are responsive to the health needs of individuals and families. Cooperative Extension and Health Science Centers can play complementary roles in addressing health needs of communities, especially those related to population health. Because each state in the nation has both a land-grant and a flagship university, the ingredients for an unprecedented and mutually beneficial collaboration in the interest of community health exists.

As evidenced in this article, there has been substantial progress in the past several years on expanding the collaboration between Cooperative Extension and the health system through a Health Extension model to better meet community needs in both urban and rural areas. It will be important to encourage dialogue between states to identify best practices for the future of this important collaboration. 
To read or post commentaries in response to this article, see it online at http://www.AnnFamMed.org/content/15/5/475.

Key words: cooperative extension; health extension; population health, community health planning

Submitted October 6, 2016; submitted, revised, February 20, 2017; accepted March 22, 2017.

\section{References}

1. Schroeder SA. Shattuck Lecture. We can do better-improving the health of the American people. N Engl J Med. 2007;357(12): 1221-1228.

2. Marmot M. Social determinants of health inequalities. Lancet. 2005;365(9464):1099-1104.

3. Wartman SA. Commentary: Academic health centers: the compelling need for recalibration. Acad Med. 2010;85(12):1821-1822.

4. Beyond Flexner Alliance. http://www.beyondflexner.org. Accessed May 19, 2017.

5. Fenton M. Health care's blind side: the overlooked connection between social needs and good health. The Robert Wood Johnson Foundation. http://www.rwjf.org/en/library/research/2011/12/healthcare-s-blind-side.html. Published Dec 2011.

6. Garg A, Jack B, Zuckerman B. Addressing the social determinants of health within the patient-centered medical home: lessons from pediatrics. JAMA. 2013;309(19):2001-2002.

7. Johnson D, Saavedra P, Sun E, et al. Community health workers and medicaid managed care in New Mexico. J Community Health. 2012;37(3):563-571.
8. Page-Reeves J, Kaufman W, Bleecker M, et al. Addressing social determinants of health in a clinic setting: The WellRx pilot in Albuquerque, New Mexico. J Am Board Fam Med. 2016;29(3):414-418.

9. Association of Public and Land-Grant Universities. Cooperative extension's national framework for health and wellness. http://www. aplu.org/document.doc?id=5134. Published Mar 2014.

10. Rodgers M, Braun B. Strategic directions for Extension health and wellness programs. J Ext. 2015;53(3):3TOT1. http://www.joe.org/ joe/2015june/tt1.php.

11. Kaufman A, Powell W, Alfero C, et al. Health extension in new Mexico: an academic health center and the social determinants of disease. Ann Fam Med. 2010;8(1):73-81.

12. Health Extension Toolkit website. http://www.healthextensiontoolkit.org. Accessed May 19, 2017.

13. Phillips RL Jr, Kaufman A, Mold JW, et al. The primary care extension program: a catalyst for change. Ann Fam Med. 2013;11(2): 173-178.

14. White S. Assessing the nation's health literacy: Key concepts and findings from the National Assessment of Adult Literacy (NAAL). Chicago, IL: American Medical Association; 2008.

15. Mitchell SM, Shortell SM. The governance and management of effective community health partnerships: a typology for research, policy, and practice. Milbank Q. 2000;78(2):241-289,151.

16. Alexander JA, Weiner BJ, Metzger ME, et al. Sustainability of collaborative capacity in community health partnerships. Med Care Res Rev. 2003:60(4 Suppl):S130-S160.

\section{Get the Annals of Family Medicine by E-mail}

Make sure you see every new issue

while it's fresh; have the table of

contents sent to you by e-mail for

easy access to articles of interest.

Don't miss important research.

Request the e-mail table of contents at

http://www2.highroadsolution.com/

aafp_annals_preference_center/search.aspx

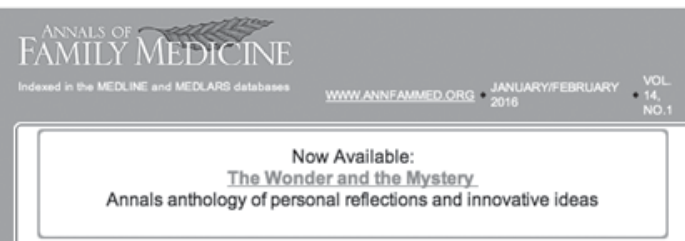

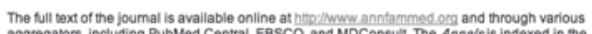

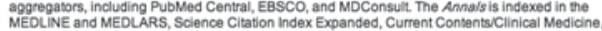
PSycINFO, EMBASE, and CINHAL databases.

EDITORIALS

In This Issuer Size Matters

Achieving PCMH Stans May Not Be Meaningtul for Small Practices

Kelley K Glancey; James Q Konnedj

The Paradox of Size: How Small, Indenpendent Practices Can Thrive in Value-Based Care
Farzad Mostasharf

ORIGINAL RESEARCH

Solo and Small Practices: A Vital, Diverse Part of Primary Care

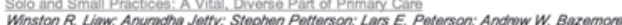
Family physicians in solo and small practices outnumber those in larger practices.

Large Indesendont Primayy Care Medical Groups

Lawrence P. Casalino; Melinda A. Chen; C. Todd Staub; Matthew J. Press; Jayme L Mendelsohn; Jahn T. Lynch; Yesenia Mirantion

Large physician-owned groups have the potential to make primary care attractive to physicians

Primary Care Physician Panel Size and Quality of Care: A Pooulation-Based Study in Ontario Simada Dahrouge; Wwiliam Hogg: Jaime Younger, Ellzabech Muggan; Grant Russell; Richard H. 